\title{
Efecto de la cafeína sobre parámetros sanguíneos de ratones con diabetes mellitus inducida por streptozotocina
}

\author{
Ruiz, S.; Lucena, E.; Linarez, R.; Matheus, N.; Mendoza, C. \\ Unidad de Investigación en Ciencias Funcionales “Dr. Haity Moussatché”(UNIHM), Facultad de Ciencias \\ Veterinarias, Universidad Centroccidental "Lisandro Alvarado", Barquisimeto, Venezuela. \\ E-mail: carmenmendoza@ucla.edu.ve
}

\begin{abstract}
Resumen
Ruiz, S.; Lucena, E.; Linarez, R.; Matheus, N.; Mendoza, C.: Efecto de la cafeína sobre parámetros sanguíneos de ratones con diabetes mellitus inducida por streptozotocina. Rev. vet. 26: 2, 120-123, 2015. La diabetes mellitus es un trastorno metabólico que afecta diferentes órganos y tejidos; su principal característica es una hiperglucemia que conduce a graves alteraciones de la salud, reduciendo la calidad de vida de los pacientes. Se ha reportado que la cafeína sería capaz de modificar el metabolismo de glúcidos, lípidos y prótidos. El objetivo de este estudio fue determinar el efecto del consumo de cafeína sobre la hiperglucemia, trigliceridemia y colesterolemia de ratones con diabetes mellitus experimental inducida por streptozotocina ( $40 \mathrm{mg} / \mathrm{kg}$ peso durante 5 días). Se utilizaron ratones de $35 \mathrm{~g}$ de peso divididos en tres grupos: controles, "diabéticos" (D) y diabéticos tratados con cafeína (C). La cafeína se administró durante 15 días en el agua de bebida a una concentración de $0,7 \mathrm{mg} /$ $\mathrm{ml}$. En los días 0, 20 y 35 se procedió a extraer sangre y determinar por espectrofotometría los niveles plasmáticos de glucosa, triglicéridos y colesterol. Los resultados se analizaron estadísticamente a través del ANOVA $(p<0,05)$. Los resultados revelaron diferencias significativas de los valores de analitos plasmáticos entre los grupos $\mathrm{C}$ y D, evidenciándose que los ratones "diabéticos" tratados con cafeína exhibieron niveles más bajos en los tres parámetros considerados. Se concluye que la cafeína es capaz de reducir los niveles sanguíneos de glucosa, triglicéridos y colesterol, por lo cual podría utilizarse en pacientes con diabetes mellitus.
\end{abstract}

Palabras clave: ratón, diabetes mellitus por streptozotocina, cafeína, reducción de glucemia, trigliceridemia y colesterolemia.

\begin{abstract}
Ruiz, S.; Lucena, E.; Linarez, R.; Matheus, N.; Mendoza, C.: Effect of caffeine on blood parameters in mice with streptozotocin-induced diabetes mellitus. Rev. vet. 26: 2, 120-123, 2015. Diabetes mellitus is a metabolic disorder affecting various organs and tissues, being its main feature the high blood glucose level that leads to a series of alterations that makes animals' everyday life challenging. It has been reported that caffeine modifies the metabolism of glucose, lipids and proteins. The aim of this study was to determine the effect of caffeine on hyperglycemia, trigliceridemia and cholesterolemia in mice with experimental diabetes mellitus. Female mice were used with an average weight of $35 \mathrm{~g}$, divided into three groups: controls, diabetic (D) and diabetics treated with caffeine (C). Diabetes was induced by the administration of streptozotocin $(40 \mathrm{mg} / \mathrm{kg}$ for 5 days). On days 0,20 and 35 blood plasma was analyzed to determine glucose, triglycerides and cholesterol. Caffeine was administered for 15 days in the drinking water at a concentration of $0.7 \mathrm{mg} / \mathrm{ml}$. Data were statistically analyzed by ANOVA $(\mathrm{p}<0.05)$. Results reveal a significant difference in the values of glucose, triglycerides and cholesterol between $\mathrm{D}$ and $\mathrm{C}$ groups. It was evident that group $\mathrm{C}$ had lower levels for all the parameters. It can be concluded that caffeine decreases blood levels of glucose, cholesterol and triglycerides and may well improve their metabolism in patients with diabetes.
\end{abstract}

Key words: mice, streptozotocin-induced diabetes mellitus, caffeine, reduction of glycemia, triglyceridemia and cholesterolemia. 


\section{INTRODUCCIÓN}

La diabetes mellitus (DM) comprende un grupo de trastornos metabólicos encabezados por una concentración elevada de glucosa en sangre. El cuadro clínico incluye, además de la hiperglucemia, glucosuria, cetosis y acidosis. Existen varios tipos de DM, cuyas diferencias se deben a una compleja interacción entre genética, factores ambientales y estilos de vida. Los de mayor incidencia son los tipos I y II ${ }^{9,10}$. Debido a la gran expansión de este trastorno, para el año 2025 el número de personas con DM en el continente americano será aproximadamente de 64 millones y el $62 \%$ de los casos ocurrirá en poblaciones de América Latina y el Caribe ${ }^{3}$. En Venezuela, la cantidad de seres humanos con DM varía entre 460.000 y 1 millón $^{2}$.

Se ha reportado que el consumo moderado de cafeína podría evitar el desarrollo de DM, debido a que aumenta el metabolismo y por ende el gasto de energía ${ }^{14}$, aunque algunos autores afirman que esta base del grupo de las xantinas sería capaz de disparar los niveles sanguíneos de glucosa ${ }^{8}$. La ingesta de café a largo plazo ha sido asociada con la reducción del riesgo de padecer diabetes mellitus ${ }^{5}$.

La cafeína es la droga psicoactiva más empleada en el mundo ${ }^{5}$. En latinoamérica el consumo promedio por persona es de $300 \mathrm{mg}$ diarios ${ }^{12}$. El alcaloide actúa como un psicoestimulante de fácil disponibilidad y amplia aceptación social, ejerciendo efectos farmacológicos en múltiples sistemas del organismo ${ }^{19,20,22,23}$. Químicamente pertenece a las metilxantinas y es un estimulante del sistema nervioso central ${ }^{15}$, provocando además relajación muscular, diuresis y broncodilatación ${ }^{7}$. Un estudio realizado en ratas demostró que la administración de cafeína por vía oral a dosis de 5 $\mathrm{mg} / \mathrm{kg}$ de peso incrementa las concentraciones séricas de catecolaminas y ácidos grasos libres, reduciendo la grasa corporal por lipólisis mediada por los agentes adrenérgicos ${ }^{13}$.

Para inducir experimentalmente la DM se han empleado diversas sustancias, entre los cuales destaca la streptozotocina (STZ), antibiótico de amplio espectro que posee propiedades antitumorales, oncogénicas y diabetogénicas ${ }^{6}$, por destrucción selectiva de las células beta de los islotes pancreáticos.

El presente trabajo tuvo como objetivo determinar el efecto de la cafeína sobre los niveles plasmáticos de glucosa, triglicéridos y colesterol en ratones NMRI con diabetes mellitus inducida por STZ.

\section{MATERIAL Y MÉTODOS}

Se utilizaron 12 ratones hembras de la cepa NMRI (Naval Medical Research Institute, USA), no consanguíneos, con un peso promedio de $30 \pm 5 \mathrm{~g}$ y 65 días de edad, provenientes del Bioterio Central de la Universidad Centroccidental "Lisandro Alvarado" (Barquisimeto, Venezuela). Los roedores fueron mantenidos bajo condiciones estandarizadas de luz y agua. Se ali- mentaron ad libitum con pellets balanceados para caninos adultos de razas grandes (Purina Dog Chow $®$ ), con altos contenidos de grasa $(10 \%)$ y proteína $(21 \%)$, cuyo consumo fue monitorizado.

Los animales se dividieron en tres grupos: control, experimental 1 y experimental 2. Cada grupo incluyó cuatro ejemplares. A los grupos experimentales 1 y 2 se les indujo diabetes por administración de una inyección intraperitoneal diaria de STZ en buffer citrato de sodio $0,05 \mathrm{M} \mathrm{pH} \mathrm{4,5} \mathrm{a} \mathrm{la} \mathrm{dosis} \mathrm{de} 40 \mathrm{mg} / \mathrm{kg}$ de peso corporal durante 5 días y a los controles solo vehículo (buffer citrato). Al día 20 de la experimentación comenzó la administración de cafeína vía oral durante 15 días en el agua de bebida al grupo experimental 2, a la concentración de $0,7 \mathrm{mg} / \mathrm{ml}$.

A todos los animales se les extrajo una muestra de sangre a partir de la vena coccígea media en los días 0,20 y 35 del experimento, con la cual se determinaron por espectrofotometría los niveles plasmáticos de glucosa (método enzimático ${ }^{21}$, kit Qualitest $₫$, Caracas, Venezuela), triglicéridos (técnica enzimática ${ }^{21}$, kit comercial Qualitest ${ }^{\circledR}$ con estándar de $200 \mathrm{mg} / \mathrm{dl}$ de trioleína) y colesterol total (técnica enzimática ${ }^{1}$, utilizando kit Colestat ${ }^{\circledR}$ de Wiener Lab., Rosario, Argentina, con un patrón de colesterol de $200 \mathrm{mg} / \mathrm{dl}$ ).

Bajo un diseño experimental completamente aleatorizado, utilizando el paquete SPSS, versión 15.0 para Windows, se realizaron estadísticas descriptivas (media aritmética, desvío estándar) e inferenciales (análisis de la variancia ANOVA a una vía). El nivel de riesgo alfa se fijó en $5 \%(\mathrm{p}<0,05)$, por debajo del cual se rechazó la hipótesis nula de igualdad.

\section{RESULTADOS}

Glucosa. Sus valores basales (día 0) fueron similares en todos los grupos. Las glucemias aumentaron significativamente a los 35 días de experimentación en los animales de los grupos experimentales 1 y 2 ; $\sin$ embargo, el incremento en los animales tratados con

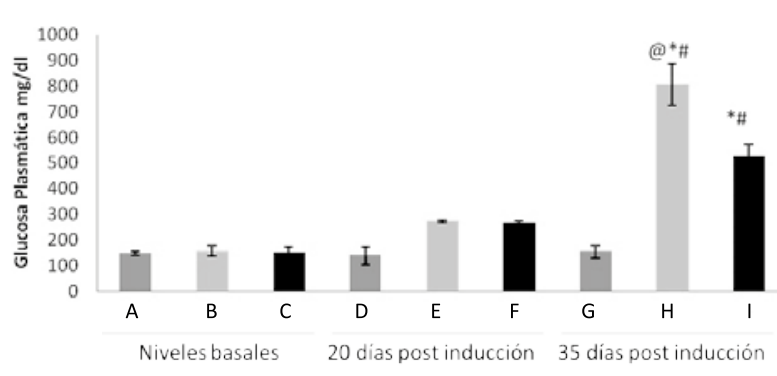

Figura 1. Evolución de la glucemia en ratones controles (A-D-G), diabéticos sin tratamiento $(\mathrm{B}, \mathrm{E}, \mathrm{H}) \mathrm{y}$ diabéticos tratados con cafeína (CFI) a los 0,20 y 35 días de experimentación. $*(\mathrm{p}<0,05)$ con respecto a su valor basal. $\#(\mathrm{p}<0,05)$ con respecto a su valor a los 20 días. @ $(\mathrm{p}<0,05)$ con respecto a los tratados con cafeína a los 35 días. Columnas señalan media aritmética; líneas verticales indican desvío estándar. 


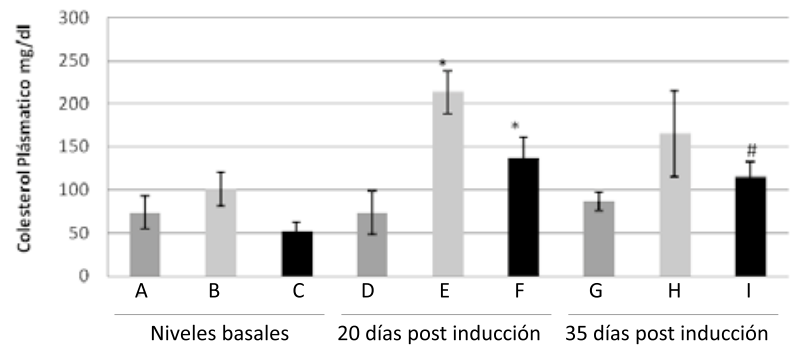

Figura 2. Evolución de la colesterolemia en ratones controles (A-D-G), diabéticos sin tratamiento (B,E,H) y diabéticos tratados con cafeína (C,F,I) a los 0,20 y 35 días de experimentación. $*(\mathrm{p}<0,05)$ con respecto a sus valores basales. $\#(p<0,05)$ con respecto a su valor a los 20 días. Columnas señalan media aritmética; líneas verticales indican desvío estándar.

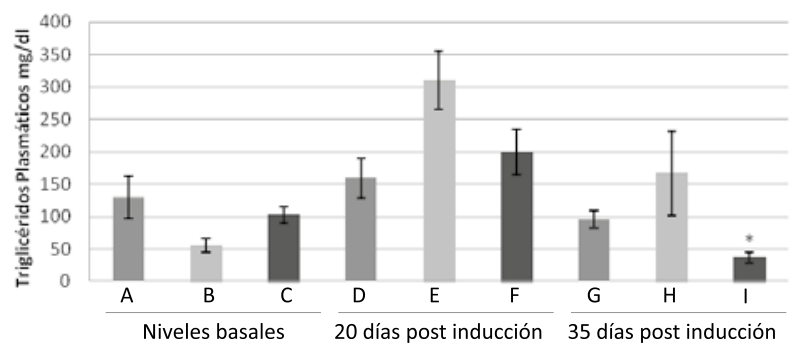

Figura 3. Evolución de la trigliceridemia en ratones controles (A-D-G), diabéticos sin tratamiento (B,E,H) y diabéticos tratados con cafeína (C,F,I) a los 0,20 y 35 días de experimentación. $*(p<0,05)$ con respecto a su valor a los veinte días. Columnas señalan media aritmética; líneas verticales indican desvío estándar.

cafeína (grupo experimental 2), fue significativamente menor al obtenido en los animales del grupo experimental 1 (Figura 1).

Colesterol. Los animales de los grupos tratados con STZ ("diabéticos") revelaron un marcado aumento en los niveles de colesterol plasmático con respecto a sus valores basales, diferencias que resultaron estadísticamente significativas $(\mathrm{p}<0,05)$. A los 35 días se observó una disminución de los niveles de colesterol en el grupo tratado con cafeína con respecto al valor obtenido a los 20 días, diferencia que también declaró significación estadística entre ambos valores (Figura 2).

Triglicéridos. Los resultados de los niveles plasmáticos de triglicéridos no resultaron homogéneos entre los tres grupos al iniciar el ensayo. Sin embargo, al avanzar la experiencia, sus variaciones fueron comparables a las obtenidos para glucosa y colesterol, registrándose una disminución significativa de sus niveles plasmáticos en los animales del grupo tratado con cafeína (Figura 3).

\section{DISCUSIÓN}

La presunción sobre el efecto benéfico de la cafeína sobre los parámetros estudiados resultó confirmada. El análisis estadístico reveló disminuciones significativas en los valores plasmáticos de glucosa, colesterol y triglicéridos en los roedores diabéticos tratados con cafeína, con relación a los diabéticos sin tratamiento.

El nivel de glucemia del grupo tratado con cafeína, fue menor tanto a los 20 como a los 35 días del experimento, indicando un posible efecto hipoglucemiante de la cafeína. Estos resultados concuerdan con los obtenidos por otros investigadores que reportan una disminución en los niveles sanguíneos de glucosa luego de una administración intraperitoneal de $37,5 \mathrm{mg} / \mathrm{kg}$ de cafeína durante 7 días ${ }^{23}$. El efecto de la cafeína sobre los niveles de glucosa aún se encuentra en discusión. Por una parte, estudios epidemiológicos a gran escala han demostrado que existe una asociación entre el consumo elevado de cafeína y la disminución del riesgo de padecer diabetes mellitus tipo II ${ }^{24}$. Otras investigaciones señalan que la cafeína, a la dosis de $5 \mathrm{mg} / \mathrm{kg}$, puede disminuir la sensibilidad celular a la insulina en seres humanos sanos ${ }^{22}$.

En el presente ensayo, a los 20 días de iniciado, se registraron significativos aumentos del colesterol plasmático de los grupos experimentales 1 y 2 ("diabéticos"), que luego descendieron notablemente a los 35 días en ambos grupos. No obstante, las concentraciones de colesterol del grupo diabético tratado con cafeína revelaron disminuciones más evidentes que las del grupo diabético no tratado con cafeína. Otros autores demostraron que, en ratas, la elevación temporal de los ácidos grasos libres después de ingerir café, no necesariamente coincide con una elevación en la concentración del colesterol plasmático ${ }^{17}$.

Al contrario de los resultados aquí obtenidos en roedores, se ha reportado que el consumo diario de cafeína en mujeres cursó con elevación de la colesterolemia ${ }^{18}$. Los autores de esta investigación concluyeron que a pesar de que el consumo de café puede no ser apropiado para todas las personas, los niveles de colesterol no se ven afectados si beben café regularmente pero con moderación (un promedio de dos tazas al día). La eficacia del café para combatir los efectos nocivos del colesterol fue demostrada por un estudio realizado en conejos a los cuales se les administró $3 \mathrm{mg}$ diarios de cafeína durante 12 semanas ${ }^{4}$.

Con respecto a los niveles plasmáticos de triglicéridos, en sendos grupos "diabéticos" de la presente experiencia, a los 20 días se constataron aumentos considerables, para luego descender a los 35 días. Tal descenso fue más acentuado en los animales del grupo experimental 2 (tratados con cafeína). Este hallazgo contrasta con los resultados obtenidos por otros investigadores, quienes habrían evidenciado que el consumo de café no parece inducir modificaciones importantes a nivel de metabolismo de lípidos ${ }^{11}$. Otra investigación realizada en personas adultas jóvenes de 18 a 35 años, quienes debieron beber café durante 15 días, concluyó que los niveles de triglicéridos aumentaron con respecto a los basales ${ }^{16}$.

Por el contrario, los resultados obtenidos en el presente trabajo son coincidentes con los reportados para 
ratas, en las cuales el consumo de cafeína durante 54 días disminuyó la concentración sérica de triglicéridos ${ }^{17}$. Este rumbo investigativo debería profundizarse a efectos de no descartar el hecho que el consumo diario de cafeína podría ser útil como tratamiento alternativo en pacientes con diabetes mellitus.

Se concluye que, a los 20 y 35 días de experimentación, en los roedores "diabéticos" investigados, las concentaciones plasmáticas de glucosa, triglicéridos y colesterol fueron menores en el grupo tratado con cafeína, indicando que este alcaloide ejerce un efecto favorable al reducir tales niveles sanguíneos.

\section{REFERENCIAS}

1. Allain C, Poon L, Chan C, Richmond W, Fu P. 1974. Enzymatic determination of total serum cholesterol. Clin Chem 20: 470-475.

2. Avilán J. 2004. Epidemiología de la diabetes en Venezuela. Gaceta Méd Caracas 112: 65.

3. Barceló A, Rajpathak S. 2001. Incidence and prevalence of diabetes mellitus in the Americas. Rev Panam Salud Públ (Washington, USA), 10: 5.

4. Chen X, Gawryluk J, Wagener J, Ghribi O, Geiger J. 2008. Caffeine blocks disruption of blood brain barrier in a rabbit model of Alzheimer's disease. J Neuroinflam 5: 120-133.

5. Donovan J, DeVane C. 2001. A primer on caffeine pharmacology and its drug interactions in clinical psychopharmacology. Psicopharmacol Bull 35: 30-48.

6. Evans J, Gerritsen G, Mann K, Owen S. 1965. Antitumor and hyperglycemic activity of streptozotocin (NSC37917) and its cofactor, U-15,774. Cancer Chemother Reports 48: 1-6.

7. Ganong W. 2010. Fisiología Médica, $23^{\circ}$ ed., Manual Moderno, México, p. 366-367.

8. Greer F, Hudson R, Ross R, Graham T. 2001. Caffeine ingestion decreases glucose disposal during a hyperinsulinemic-euglycemic clamp in sedentary humans. Diabetes 50: 2349-2354.

9. Guyton A, Hall J. 2001. Tratado de Fisiología Médica, $10^{\circ}$ ed., McGraw Hill, México, p. 1066.

10. Harrison T. 2006. Principios de Medicina Interna, $16^{\circ}$ ed., McGraw Hill, México, p. 2367-2368.

11. Hejda S, Osancova K, Cervenkova D. 1988. Coffee and blood lipids. Ernahrung 12: 796-800.
12. Higdon J, Frei B. 2006. Coffee and health: a review of recent human research. Critical Rev Food 46: 101-123.

13. Kobayashi-Hattori K, Mogi A, Matsumoto Y, Takita T. 2005. Effect of caffeine on the body fat and lipid metabolism of rats fed on a high-fat diet. J Bioscience, Biotechnology \& Biochemestry 69: 2219-2223.

14. Naismith D, Akimyanju P, Yudkin J. 1989. Influence of caffeine-containing beverages on the growth, food utilization and plasma lipids of the rat. J Nutrition 97: 375-381.

15. Nawrot P, Jordan S, Eastwood J, Rotstein J, Hugenholtz A, Feeley M. 2003. Effects of caffeine on human health. Food Addit Contam 20: 1-30.

16. Ortiz MS. 2011. Efectos del consumo del café sobre el metabolismo de glucosa y triglicéridos en adultos jóvenes. Publ. Instit Invest Salud Públ, Univ Sierra Sur, México. On line: contenidosabiertos.academica.mx/jspui/handle/987654321/578

17. Rakicioglu N, Pekcan G, Cevik A. 1998. The effect of coffee and caffeine consumption on serum lipids in rats. Int J Food Sci Nutr 49: 441-447.

18. Shirlow M, Wathers C. 1984. Caffeine consumption and serum cholesterol levels. Int J Epidemiol 13: 422-427.

19. Taylor S, Demmig-Adams B. 2007. To sip or not to sip: the potential health risks and benefits of coffee drinking. Nutr \& Food Sci 37: 406-418.

20. Thong F, Derave W, Kiens B, Graham T, Urso B, Wojtaszewski J, Richter E, Hansen B. 2002. Caffeineinduced impairment of insulin action but not insulin signaling in human skeletal muscle is reduced by exercise. Diabetes 51: 583-590.

21. Trinder P. 1969. Determination of blood glucose using an oxidase-peroxidase system with a non-carcinogenic chromogen. J Clin Pathol 22: 158-161.

22. Urzua Z. 2011. Efectos crónicos de la cafeína sobre el nivel y tolerancia a la glucosa en ratas sanas y con diabetes mellitus experimental. Tesis Doctoral, Universidad de Colima, Méjico, $47 \mathrm{p}$.

23. Van Dam R, Pasman P, Verhoef P. 2004. Effects of coffee consumption on fasting blood glucose and insulin concentrations randomized controlled trials in healthy volunteers. Diabetes Care 27: 2990-2992.

24. Van Dam R, Hu F. 2005. Coffee consumption and risk of type 2 diabetes: a systematic review. JAMA 294: 97-104. 